\title{
CONFLUENT AND RETICULATE PAPILLOMATOSIS: A REPORT OF TWO CASES
}

\author{
R. Rama1 ${ }^{1}$ B. Indira², P. Guru Prasad 3 , S. Jhansi Lakshmi4 ${ }^{4}$ Shravya ${ }^{5}$
}

\section{HOW TO CITE THIS ARTICLE:}

R. Rama, B. Indira, P. Guru Prasad, S. Jhansi Lakshmi, Shravya. "Confluent and Reticulate Papillomatosis: A Report of Two Cases". Journal of Evolution of Medical and Dental Sciences 2015; Vol. 4, Issue 27, April 02; Page: 4722-4725, DOI: 10.14260/jemds/2015/684

\begin{abstract}
Confluent and reticulate papillomatosis was first described in 1927 by GougerotCarteaud (C.R.P). It is an uncommon dermatoses affecting young individuals characterised by assymptomatic multiple brownish scaly papules coalesced to form reticular pattern peripherally and confluent plaques centrally in inter-mammary, inter-scapular areas, shoulder \& arms. Disease begins in late teens \& have sex distribution \& affects white blacks \& Asian patients. Though the exact etiopathogenesis is not known, many theories were proposed regarding obesity, defective keratinisation, exposure to UV-light, endocrine imbalance \& abnormal host response to malassezia furfur, recently it was proposed that it is probably a reaction pattern to bacterial infection in susceptible individuals resulting in epidermal proliferation. Minocycline is a good choice for C.R.P. here we report 2 cases of C.R.P. responding well to minocycline.
\end{abstract}

KEYWORDS: Confluent \& reticulate papillomatosis, minocycline.

\section{CASE REPORT:}

Patient-1: A 36 years old male patient was presented to our dermatology department with itchy reddish brown papular lesions on the upper trunk \& neck since 1 year duration. The lesions initially appeared on inter mammary \&inter scapular areas, later spread to the upper arms \&neck. He used topical ketoconazole preparation but there was no improvement. He denied family history of similar lesions and there were no other complaints.

On examination his general condition was good, obese. Cutaneous examination the lesions were well-defined, reddish brown, multiple warty papules of 2-4 $\mathrm{mm}$ in size on the inter mammary, inter scapular areas, upper arms \& neck. The lesions on the upper back were confluent centrally \& peripherally in a reticulated pattern. (Fig. $1 \& 2$ ).

Microscopic examination of scrapings in $10 \%$ koh wet mount did not show any filaments or spores of malassezia furfur. Histopathological examination (Fig. 3 \& 4) of skin biopsy showed hyperkeratosis, acanthosis, papillomatosis \& increased pigmentation in the basal layer. Basement membrane is intact. There is mild perivascular lymphocytic infiltrates, melanophages in the upper dermis. Basing on history, clinical examination \&biopsy findings a diagnosis of confluent and reticulate papillomatosis was made.

Patient-2: A 22 year old male patient presented with 1 year history of reticular pigmented lesions on trunk both upper \& lower limbs. There was history of seborrhoea. He denies family history of similar lesions \& there were no other complaints. On examination he had reddish brown reticular pigmented lesions on both upper limbs more so over right forearm then on the left side. Scaling is present in some areas. Hyper pigmented scaly macular lesions present on front of chest \& upper back. 10\% koh wet mount examination showed no fungal elements. 
On histopathological examination epidermis shows mild hyper keratosis, focal para keratosis, mild hyper granulosis and acanthosis. Basal layer is intact. Upper dermis shows proliferative thin walled vessels, perivascular edema \& mild lymphocytic infiltrate. Based on history, clinical examination, histo pathological examination a diagnosis of confluent reticulate papillomatosis was made.

DISCUSSION: CRP is rare genetically determined defect of keratinisation characterised by persistent asymptomatic warty papular lesions of characteristic distribution with tendency to become confluent centrally \& peripheral reticulated pattern.(1) Though the etio pathogenesis is still not precisely known, occurence of C.R.P in family members suggest genetic factors.(2),(3) Most of the cases are obese.(4) C.R.P affects both the sexes equally. In this report 2 cases are males \& both denied history of similar complaints in the family. Previous case reports suggest that there is abnormality of the host response to colonisation by malassezia furfur.(5) Above 2 cases did not show any fungal filaments or spores. in some reports actinomycete is isolated from the skin of an immmuno competent patients with CRP.(6),(7)

Though oral azithromycin is successful(8) minocycline is highly effective in most of the patients. (9) Minocycline possess both anti-inflammmatory \& anti-microbial property. But the response to these specific antibiotic may be related more to their anti-inflammmatory properties rather than anti-microbial effect. Minocycline inhibits migration of neutrophils. Prevents release of reactive oxygen species\& inhibits matrix-metalloproteinase.(10)(11)(12) In both cases lesions were completely cleared in 3 weeks suggesting that the bacterial infection might be the cause. Hence minocycline is effective in healing these condition.

\section{REFERENCES:}

1. M. P. Binitha, v.laxmi nair: Confluent \&reticulate papillomatosis 1990 volume 56 issue page 4849.

2. Baden M.P: famial cutaneous papillomatosis arch dermatol 1965: 92 394-395.

3. Heming J.P de wit RF- familial occurrence of crp arch dermat 1981, 117, 809-10.

4. Watkins DM AND LOCKWOOD JH - confluent \&reticulate papillomatosis. Arch.dermatol. 1957, 76, 648-651.

5. Kesten BM \& James HD: pseudoatrophoderma colli, acanthosis nigricans and confluent and reticulate papilomatosis, arch dermatol 1957; 75: 525-542.

6. INT J syst E vol microbial 2008, 58. 68-72.

7. Keshava Murthy A Adye; Arun C Inmdar aparna palit - reticulate papilomatosis IJD 2014vol 59 issue p3-14.

8. Rajababu k.k. snehel s.sudhavani D. Confluent \&reticulate papillomatosis successful treatment with azithromycin BrJ. DERMATOL 2000 142: 125 2-3.

9. Davis MD. Weening RH Camilleri MJ: confluent \& reticulate papillomatosis (gongerout castaend syndrome) a minocycline responsive dermatosis without evidence for yeast in pathogenesis. A study of 39 patients and a proposal diagnostic criteria Br. J. dermatol 2006. 154: 287-93.

10. Chang S. N. Kimse Leesh, Leews. Minocycline treatment for confluent \&reticulate papilomatosis 1996, 57, 454-7. 


\section{CASE REPORT}

11. Rao T. Guruprasadp. sowjanyac, naga sridevi- Indian journal of dermatology, venereology \& leprosy 2010: 76(6): 725.

12. Tugenyu, yicao, xiao hong yanget al- two cases of C.R.P successfully treated with Chinese drug I.J.D 2009.VOLUME 54.ISSUE 5.PAGE 60-62.

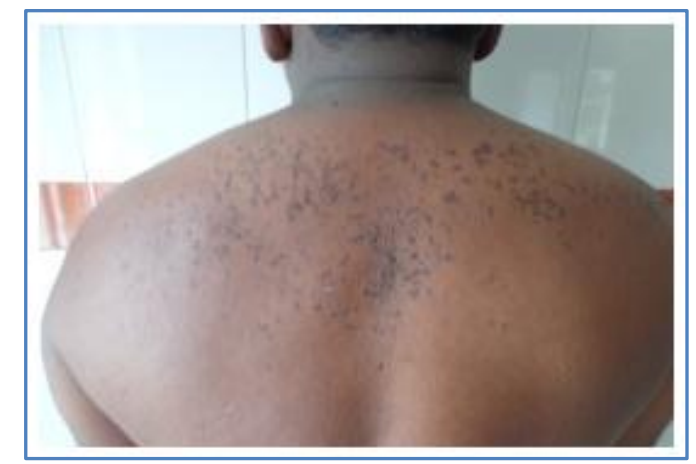

Fig. 1: Hyperpigmented warty papules over inter scapular area

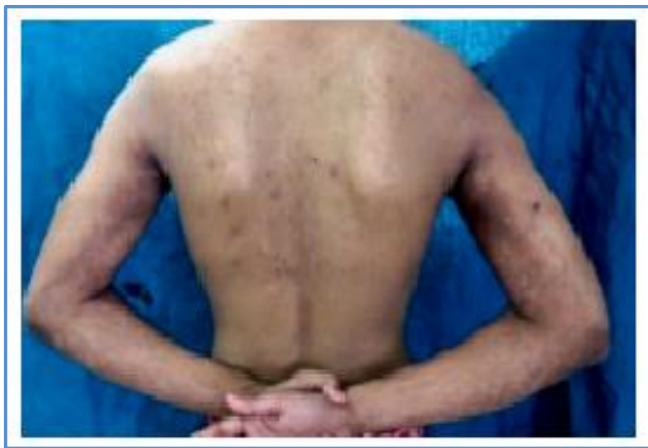

Fig. 3: Hyperpigmented macules over inner aspect of fore arm

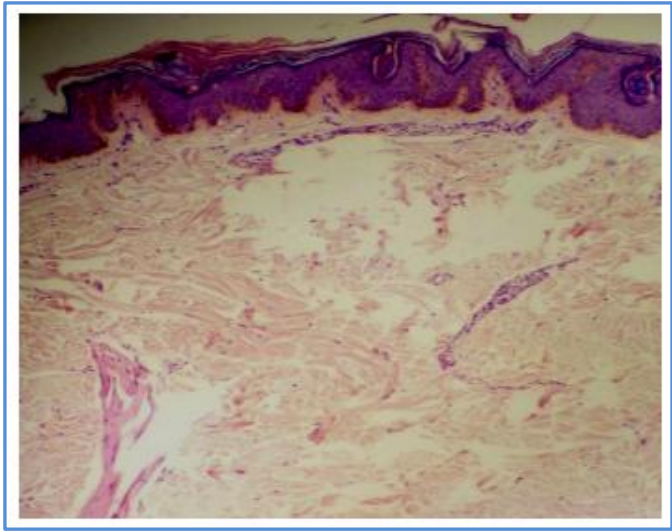

Fig. 5: 10x : 10xhyperkeratosis, acanthosis, papillomatosis \& increased pigmentation in the basal layer

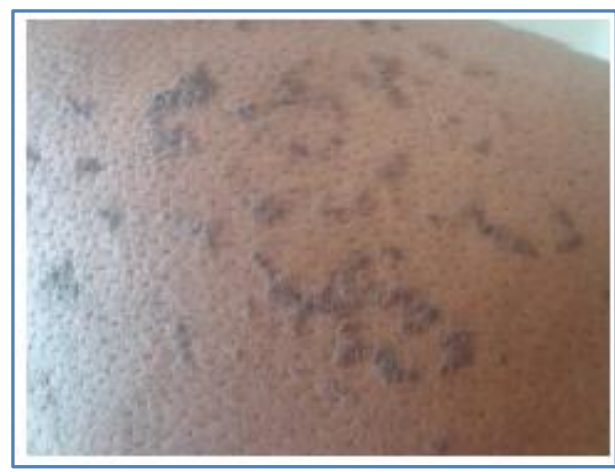

Fig. 2: Warty papuls showing confluence and reticulate pattern

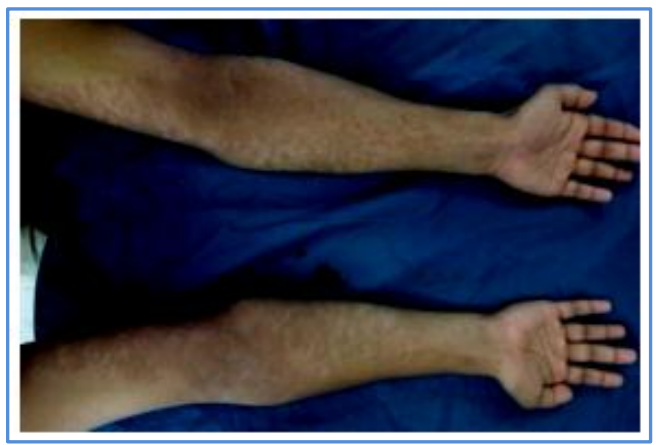

Fig. 4: Papules and warty lesions over fore arms

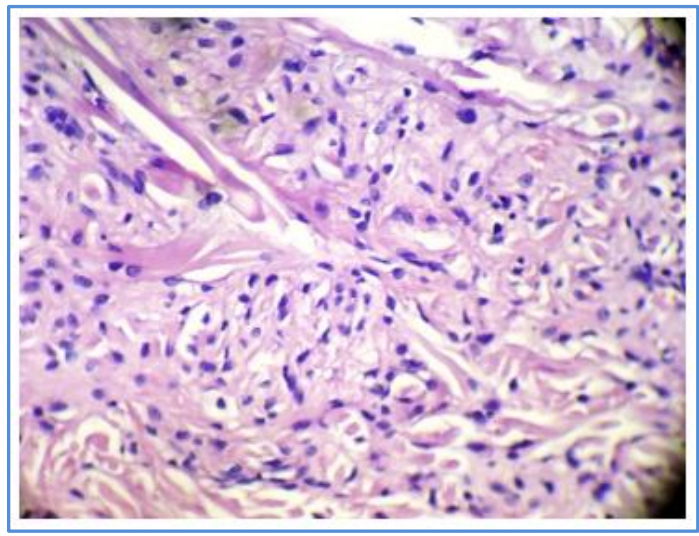

Fig. 6: 40x : High power perivascular lymphocytic infiltrates 


\section{CASE REPORT}

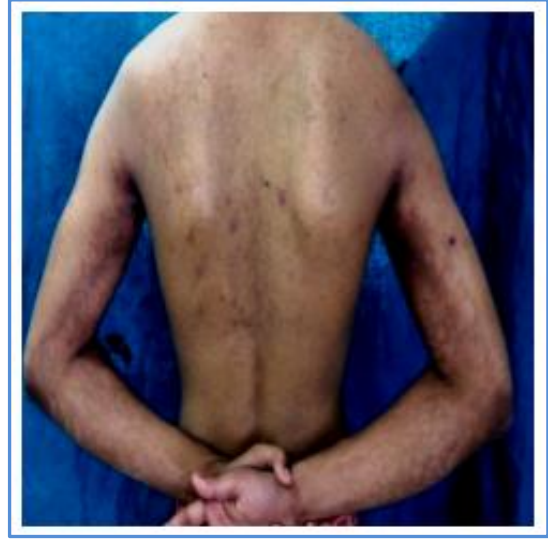

Fig. 7: Before treatment

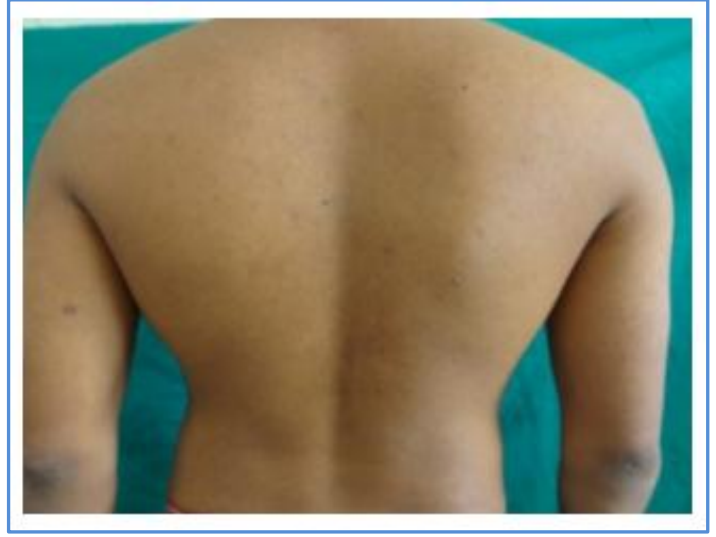

Fig. 8: After treatment

\section{AUTHORS: \\ 1. R. Rama \\ 2. B. Indira \\ 3. P. Guru Prasad \\ 4. S. Jhansi Lakshmi \\ 5. Shravya}

\section{PARTICULARS OF CONTRIBUTORS:}

1. Assistant Professor, Department of Dermatology, Venereology \& Leprosy, Andhra Medical College, Visakhapatnam.

2. Assistant Professor, Department of Dermatology, Venereology \& Leprosy, Andhra Medical College, Visakhapatnam.

3. Associate Professor, Department of Dermatology, Venereology \& Leprosy, Andhra Medical College, Visakhapatnam.

FINANCIAL OR OTHER

COMPETING INTERESTS: None
4. Assistant Professor, Department of Dermatology, Venereology \& Leprosy, Andhra Medical College, Visakhapatnam.

5. Junior Resident, Department of Dermatology, Venereology \& Leprosy, Andhra Medical College, Visakhapatnam.

\section{NAME ADDRESS EMAIL ID OF THE CORRESPONDING AUTHOR:}

Dr. P. Guru Prasad, Associate Professor, Department of Dermatology, Venereology \& Leprosy, Andhra Medical College, Visakhapatnam.

E-mail: gppatnala@yahoo.co.in

Date of Submission: 23/02/2015. Date of Peer Review: 24/02/2015. Date of Acceptance: 23/03/2015. Date of Publishing: 02/04/2015. 